\title{
Synthesis of hierarchically porous bioactive glasses using natural plants as template for bone tissue regeneration
}

\author{
Xiaofeng Li $\cdot$ Fengyu Qu $\cdot$ Wang Li $\cdot$ \\ Huiming Lin · Yingxue Jin
}

Received: 25 November 2011/Accepted: 12 May 2012/Published online: 23 May 2012

(C) The Author(s) 2012. This article is published with open access at Springerlink.com

\begin{abstract}
A series of highly ordered hierarchically porous silica and bio-glasses materials with macropore size of $8-1,000 \mu \mathrm{m}$ and mesopore size of 3.1-5.6 $\mathrm{nm}$ have been synthesized using six plant based materials as templates. However, the as-obtained porous structure was reported for the first time with interconnected 3D macropore up to $1,000 \mu \mathrm{m}$. The porous silica materials were used as the host for drug loading and release, which showed a good sustained delivery function. The as-synthesized bio-glasses materials indicated the highly bioactive capability in the bone regeneration. This method can be utilized to synthesize other multi-porous bioactive glasses using different plants as templates for bone tissue repairing.
\end{abstract}

Keywords Hierarchically pore silica - Bio-glasses - Plant template $\cdot$ Drug release $\cdot$ Osteogenic property

\section{Introduction}

Hierarchically porous materials have received enormous attention due to the multiple dimensions of their pore structures, high surface area and complex morphologies [1]. These materials combine the advantages of the two kinds of pores: macropores can improve diffusion and transport of large molecules, and the high surface area and large pore volumes of mesopores are beneficial for loading

X. Li $(\bowtie) \cdot$ F. Qu · W. Li · H. Lin · Y. Jin

College of Huarui, Northeast Petroleum University, Harbin

150025, People's Republic of China

e-mail: lixiaofeng8578@yahoo.com.cn

X. Li · F. Qu • W. Li · H. Lin · Y. Jin

College of Chemistry and Chemical Engineering, Harbin Normal

University, Harbin 150025, People's Republic of China large amounts of guest molecules. Thus, the materials will have promising prospects for industrial processes involving catalysis, adsorption, separation, chemical sensing, storage of fluids and gases in transportation [2-4], and enzyme immobilization [5]. Generally, hierarchical porous materials have been prepared by multiple template methods, including hard templates for macropores [6-13], and soft templates for preparation of meso-/micro-pores [14]. Constructing novel hierarchically porous materials with natural biological templates is an brand-new field. They have many advantages compared to artificial ones due to their abundant, renewable, and environmentally friendly properties. They also have various structures, splendid morphologies, and good biocompatibilities [1, 15-17]. At present, all kinds of biological materials have been used as hard template such as plants: wood [18], bamboo [19], diatoms [20]; animal tissue: cuttlebone [21], echinus bone [22-29]. However, the materials prepared by these natural templates contain only 1-5 $\mu \mathrm{m}$ wide macropores in general. So far, few highly ordered hierarchically porous materials have been synthesized with macropores bigger than $10 \mu \mathrm{m}[18,19]$ using natural plants as template.

Recently, these hierarchically porous materials have been used in tissue regeneration. Ideally, a scaffold for bone repaired should have three important characteristics: (1) an interconnected framework with large pores $(>10 \mu \mathrm{m})$ to enable tissue growth and nutrient delivery to the center of the regenerated tissue; (2) a large specific BET surface area provided by a microporous or mesoporous phase to promote cell adhesion, drug storage and delivery, and adsorption of biologic metabolites [30-33]; (3) a favorable bio-compatibility (i.e. the formation capability of hydroxyapatite (HAP) for repairing of bones).

Bioactive glasses (BGs) have been an interesting topic since the pioneering work by Hench et al. [34]. To date 
macro-/meso-porous bioactive glasses (MMBGs) have been studied by several research groups for bone tissue regeneration [35-38]. These reports focus mainly on the synthesis of BG materials using granular polyethylene glycol, methyl cellulose and polyurethane sponges as macropore templates and nonionic block copolymers as mesopore templates. Osteogenic properties of multi-level pore materials were also studied. Till now, no BGs with macropore size larger than $10 \mu \mathrm{m}$ have been synthesized using natural templates.

In this paper, we successfully synthesized a series of highly ordered hierarchically porous silica materials with macropore sizes ranging between 8 and $1,000 \mu \mathrm{m}$ and mesopore sizes between 3.1 and $5.6 \mathrm{~nm}$ using six plants as templates for macropores and the block copolymer P123 as mesopore template. To the best of our knowledge this is the first report about hierarchically pore structures with interconnected 3D macropores up to $1,000 \mu \mathrm{m}$. In addition, ibuprofen (IBU) was employed as a model drug to study the drug loading/release profiles of these silica materials. Furthermore, we achieved the first synthesis of a hierarchical porous bioactive glass scaffold using plants and P123 as co-template by adding calcium and phosphate ions during synthesis of the silica materials. The BGs also exhibit a hierarchical structure with interconnected macropores (about 20-200 $\mu \mathrm{m}$ ) and 3.1-4.1 nm wide mesopores, the bioactivity of the BGs for bone tissue regeneration was simultaneously investigated revealing superior in vitro bone-forming bioactivities of the prepared BGs.

\section{Experimental section}

\subsection{Materials}

All the chemicals were purchased from commercial sources and used without further purification: $\mathrm{EO}_{20} \mathrm{PO}_{70} \mathrm{EO}_{20}$ (P123, Aldrich Chemical Co., USA), Tetraethoxysilane (TEOS, Tiantai Co., Tianjin China), hydrochloric acid and ethanol (EtOH, Harbin Chemical Co., Harbin, China), calcium nitrate tetrahydrate $\left(\mathrm{Ca}\left(\mathrm{NO}_{3}\right)_{2} \cdot 4 \mathrm{H}_{2} \mathrm{O}\right.$, Tianjin Chemical Co., Tianjin, China), triethyl phosphate (TEP, Shenyang Chemical Co., Shenyang, China) and ibuprofen (IBU, Tianjin Chemical Co., Nanjing). Plants were obtained from Harbin, China.

\subsection{Characterization}

Samples were characterized by X-ray diffraction (XRD) using a SIEMENS D5005 diffractometer with $\mathrm{Cu} \mathrm{K} \propto$ radiation at $40 \mathrm{kV}$ and $30 \mathrm{~mA} . \mathrm{N}_{2}$ adsorption/desorption isotherms were measured at liquid nitrogen temperature using a Micromeritics ASAP 2010M system. The pore sizes distributions were calculated from the adsorption branches of the $\mathrm{N}_{2}$ adsorption isotherms using the BarrettJoyner-Halenda (BJH) model. Scanning electron microscopy (SEM) was performed using a Hitachi S-4800 instrument operated at an accelerating voltage of $200 \mathrm{kV}$. An SEM-EDS accessory was used to observe the HAP growth on the surfaces of samples. Transmission electron microscopy (TEM) images were recorded on JEOL $2010 \mathrm{~F}$ and Philips CM200 FEG instruments with an acceleration voltage of $20 \mathrm{kV}$. UV-vis spectra were measured on a 752 Spectrophotometer made in Shanghai. The concentrations of $\mathrm{Ca}, \mathrm{P}$, and $\mathrm{Si}$ in simulated body fluid (SBF) solutions were determined by inductively coupled plasma atomic emission spectroscopy (ICP-AES; Varian Co., USA) before and after soaking of plant.

\subsection{Synthesis of hierarchical porous materials}

In a typical procedure, a surfactant solution was prepared by adding $0.9 \mathrm{~g} \mathrm{P} 123$ to a mixed solution containing $10.0 \mathrm{~g}$ of ethanol, $0.8 \mathrm{~g}$ of water and $0.1 \mathrm{~g}$ of $2 \mathrm{~mol} \mathrm{~L}^{-1}$ hydrochloric acid, and then $2.08 \mathrm{~g}$ TEOS was added. The mixture was stirred for $2 \mathrm{~h}$, the dried plants were cut into $1 \times 1 \mathrm{~cm}^{3}$ including calla peel, paulownia stem, poplar stem, abutilon stem, artichoke stem and calla stem, and than they were soaked in the solution for 3 days at $60{ }^{\circ} \mathrm{C}$ in a sealed polypropylene container. The plant based materials were then removed from the solution and re-soaked in a new solution for another 3 days at $60{ }^{\circ} \mathrm{C}$. Finally, the samples were taken out from the sol-like mixture, air-dried, and calcined at $550{ }^{\circ} \mathrm{C}$ for $5 \mathrm{~h}$ in air. The obtained hierarchical porous materials were named as HPM1 (calla peel), HPM2 (paulownia stem), HPM3 (poplar stem), HPM4 (abutilon stem), HPM5 (artichoke stem) and HPM6 (calla stem), respectively.

\subsection{Drug load and release profiles}

For the studies of IBU release, HPM4 and HPM5 were selected randomly as samples. A typical drug release experiment was performed as follows: $206 \mathrm{mg}$ of porous composite material and $206 \mathrm{mg}$ of IBU were dispersed in $10 \mathrm{ml}$ of $\mathrm{n}$-hexane solution by stirring for $2 \mathrm{~h}$ at room temperature. Then the loaded samples were separated from the solution by vacuum filtration and dried under ambient conditions. The filtrates were diluted by $n$-hexane solution and the amount of loaded IBU was measured with the UVvis spectrophotometer.

The release profiles of the samples were obtained by soaking the drug-loaded powders in phosphate buffer solution $(\mathrm{pH}=6.8)$. The release experiment was performed at $37{ }^{\circ} \mathrm{C}$. At predetermined time intervals, $3 \mathrm{ml}$ of sample was withdrawn and another $3 \mathrm{ml}$ of fresh phosphate 
buffer solution was added immediately. The withdrawn samples were diluted to $25 \mathrm{ml}$ and the drug concentration in the sampled fluid was measured with the UV-Vis spectrophotometer.

\subsection{Preparation of the MMBG scaffolds}

The mesopore/macropore bioactive glass scaffolds (MMBGs) were synthesized by using nonionic block copolymer P123 and plant peelings as co-templates. In a typical synthesis, P123 (4.0 g), TEOS $(6.7 \mathrm{~g}), \mathrm{Ca}\left(\mathrm{NO}_{3}\right)_{2} \cdot 4 \mathrm{H}_{2} \mathrm{O}(1.4 \mathrm{~g})$, TEP $(0.73 \mathrm{~g})$, and $0.5 \mathrm{~mol} \mathrm{~L}^{-1} \mathrm{HCl}(1.0 \mathrm{~g})$ were dissolved in ethanol $(60 \mathrm{~g})$ and stirred at room temperature for 1 day. Afterwards, paulownia stem, artichoke stem, and abutilon stem were immersed into the solution for 3 days at $60{ }^{\circ} \mathrm{C}$ in a sealed polypropylene container. After evaporating the solution for $24 \mathrm{~h}$ at room temperature, the samples were re-soaked in a new solution for another 3 days at $60{ }^{\circ} \mathrm{C}$. Finally, the samples were taken out from the sol-like mixture, air-dried, and heated at a slow rate of $2{ }^{\circ} \mathrm{C} / \mathrm{min}$ to $550{ }^{\circ} \mathrm{C}$ to obtain the final MMBG scaffolds named as MMBG1 (paulownia stem), MMBG2 (artichoke stem) and MMBG3 (abutilon stem).

\subsection{In vitro bioactivity of the MMBG scaffolds in SBF}

The assessment of the in vitro bioactivity of the MMBG scaffolds was carried out in SBF. The SBF solution had a composition and ionic concentrations similar to those of human plasma [39]. MMBG1, MMBG2 and MMBG3 were used to investigate the bioactivity. Each type of MMBG was soaked in $100 \mathrm{ml}$ SBF solution in a polyethylene bottle at $37{ }^{\circ} \mathrm{C}$. The ratio of MMBG powder weight to SBF solution volume was $1.5 \mathrm{mg} / \mathrm{ml}$ [40]. The samples were taken out from the SBF solutions after soaking for 1, 3, 5 or 7 days, then rinsed with acetone and air-dried at room temperature.

\section{Results and discussion}

\subsection{Characterization of the porous composite materials}

Figure 1 shows the morphologies of the macroporous scaffolds by SEM images. It can be seen that the six samples exhibited different pore structures. HPM1 and HPM2 have smaller pore size $(8-10 \mu \mathrm{m})$, while HPM3 and HPM4 both have two sets of macropores whose sizes are $8-10,30-40 \mu \mathrm{m}$ and $8-10,60-80 \mu \mathrm{m}$, respectively. The pore size of HPM5 decreases gradually from the edge $(200 \mu \mathrm{m})$ to the center $(80 \mu \mathrm{m})$, and the pore size of HPM6 ranges between 500 and $1,000 \mu \mathrm{m}$.

Figure 2a shows the small angle XRD patterns of several hierarchically pore silicon. HMP4 and HMP5 clearly show a [100] peak, which indicates that these samples possess a hexagonally ordered mesoporous structure. The three MMBGs show very weak diffraction peaks (Fig. 2b) compared to the pure silicon materials, indicating that the mesopore structure is different with the addition of $\mathrm{Ca}$ and
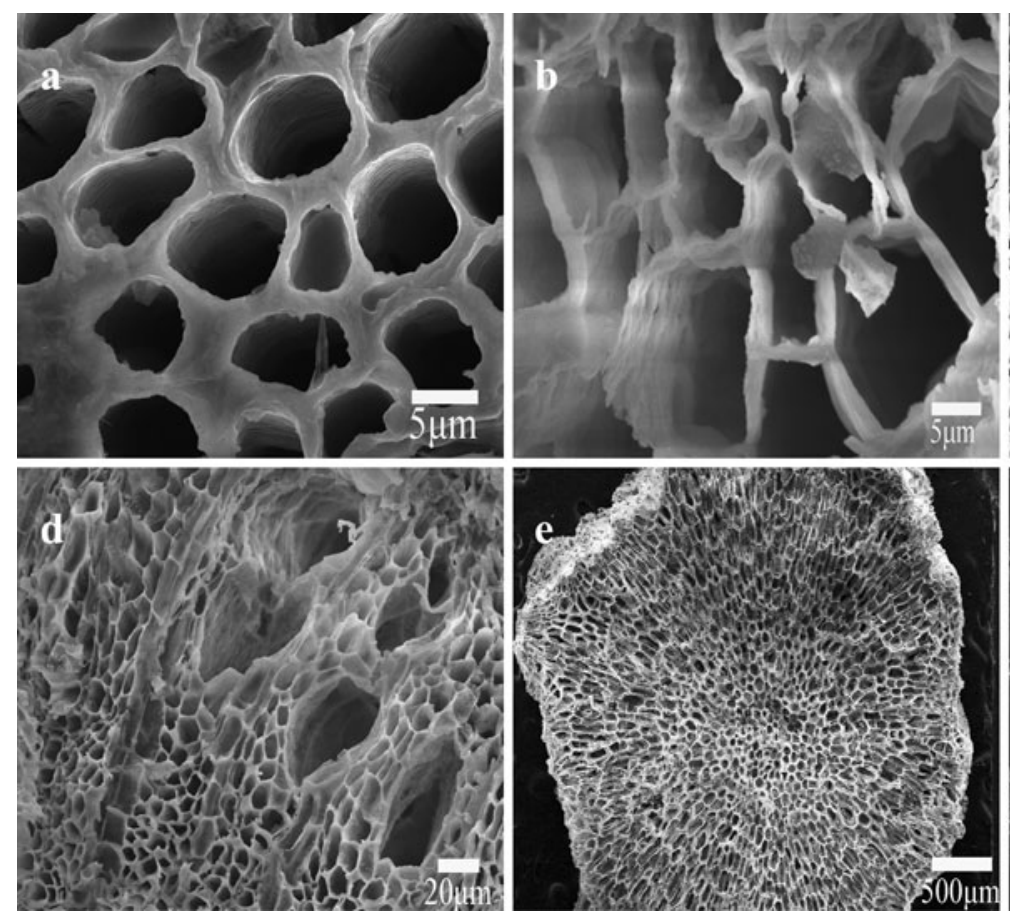

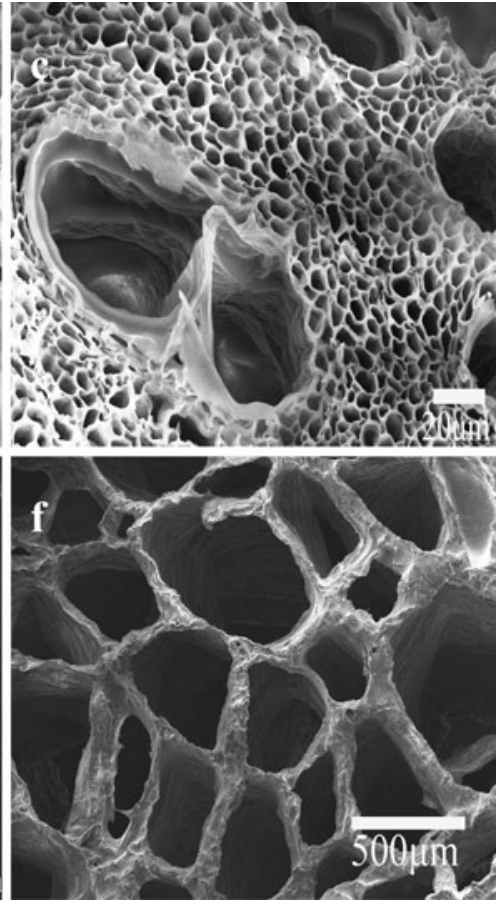

Fig. 1 SEM image hierarchically macro/meso scaffolds a HPM1, b HPM2, c HPM3, d HPM4, e HPM5, f HPM6 
Fig. 2 XRD patterns of samples at low diffraction angles a HMP4, HMP5, b MMBG1, MMBG2 and MMBG3
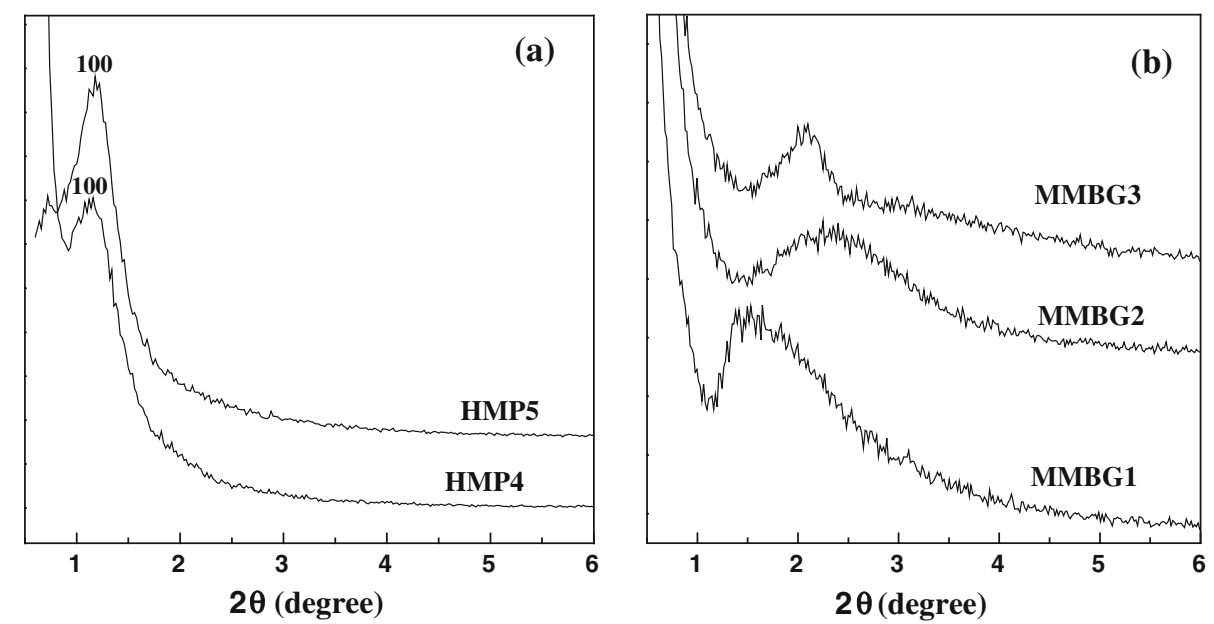

P. TEM images confirm the highly ordered hexagonal pore arrangement (Fig. 3).

The nitrogen adsorption-desorption isotherms and the corresponding pore size distributions of all samples (Fig. 4) indicate a type IV isotherm. The surface areas, pore volumes and sizes are listed in Table 1 . It can be seen that all samples possess large volumes from 0.23 to $0.4 \mathrm{~cm}^{3} / \mathrm{g}$ and the specific BET surface area reaches $300-420 \mathrm{~m}^{2} / \mathrm{g}$. Narrow peaks in the BJH pore-size distributions are centered at $3.13-5.56 \mathrm{~nm}$. It can be inferred that the mesoporosity provides a way for loading larger amounts of guest molecules, by which could improve in vitro bioactivity.

Each plant consists of cellulose, hemicellulose and lignin, interconnected vessels, tracheids and sieve tubes are contained in each part of the plant. The primary as-synthesized sol is a homogeneous solution. After soaking of plant into the solution, the silicate species were mineralized in the inner of the vessels, tracheids and sieve tubes. After the calcination, the silica scaffold preserved the original
Fig. 3 TEM images of a HMP4, b HMP5 recorded along the [100] directions, c MMBG1, d MMBG2 recorded along the [001] directions
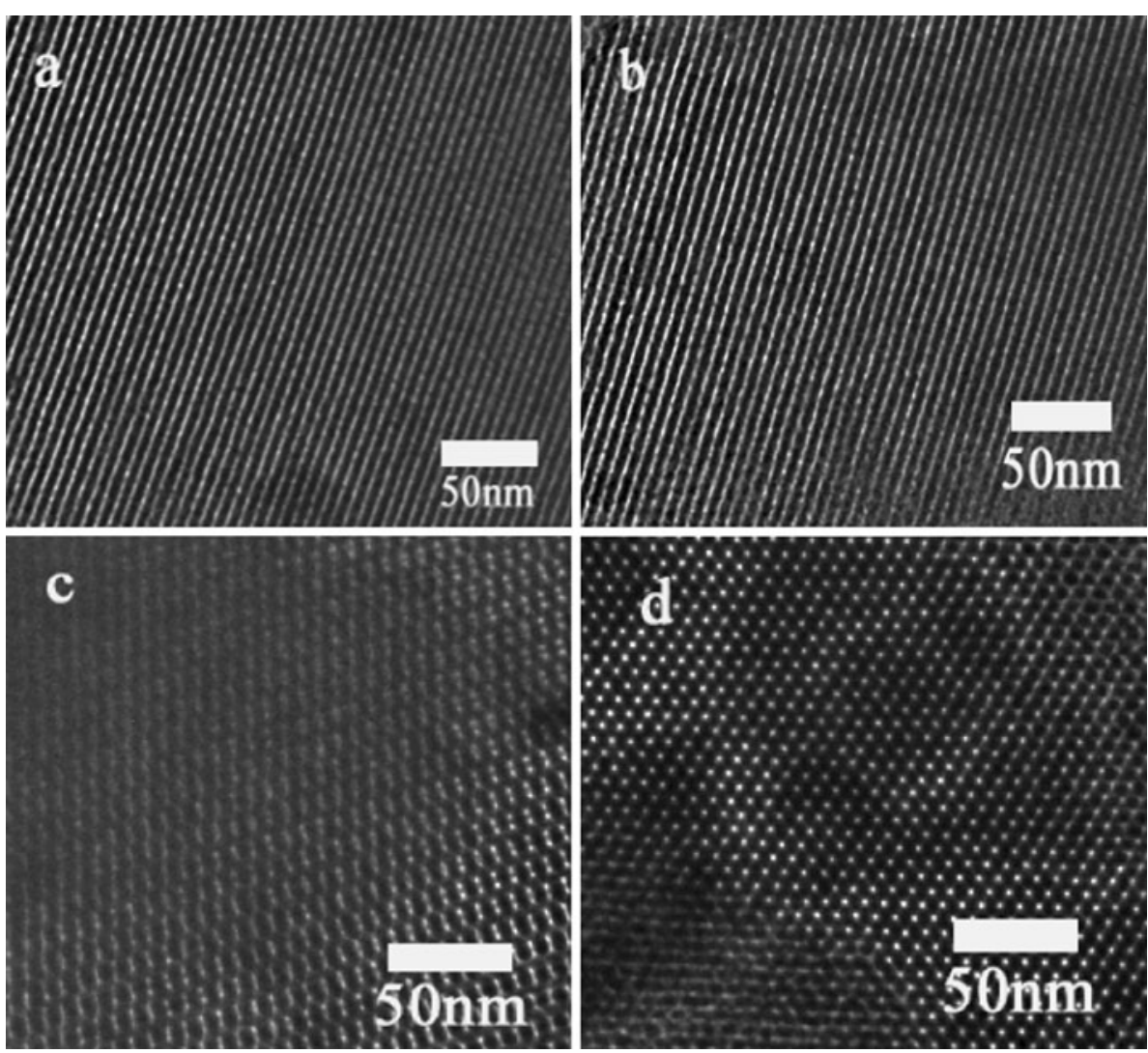
Fig. 4 Nitrogen adsorption/ desorption isotherm and mesopore distribution of the samples a HMP4, HMP5, b MMBG1, MMBG2 and MMBG3

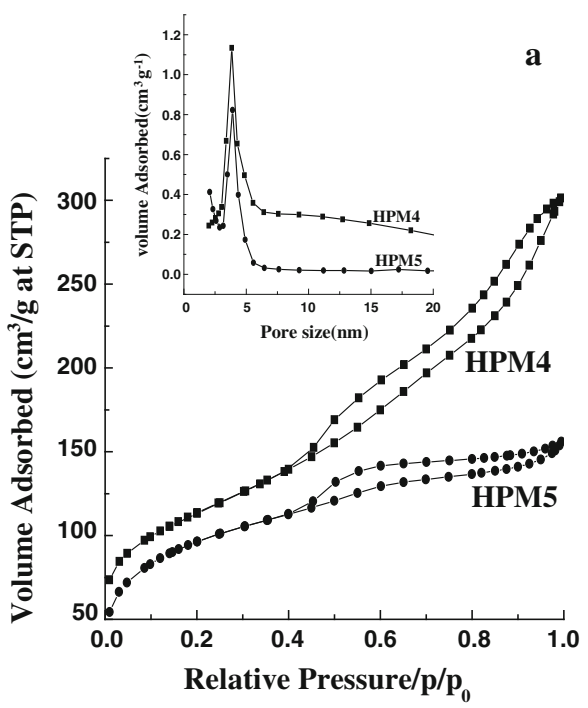

Table 1 BET surface area pore volume and average pores diameter of the samples

\begin{tabular}{llll}
\hline Sample & $\begin{array}{l}\text { BET surface } \\
\text { area }\left(\mathrm{m}^{2} / \mathrm{g}\right)\end{array}$ & $\begin{array}{l}\text { Pore volume } \\
\left(\mathrm{cm}^{3} / \mathrm{g}\right)\end{array}$ & $\begin{array}{l}\text { Average pore } \\
\text { diameter }(\mathrm{nm})\end{array}$ \\
\hline HPM4 & 306.03 & 0.40 & 5.56 \\
HPM5 & 347.56 & 0.23 & 3.75 \\
MMBG1 & 420.85 & 0.35 & 3.52 \\
MMBG2 & 409.49 & 0.30 & 3.13 \\
MMBG3 & 299.25 & 0.29 & 4.13 \\
\hline
\end{tabular}

morphologies and structure of the plants, and "tube" types have been replicated so that macroporous materials were obtained [41].

\subsection{Drug release of hierarchically pore silica}

Figure 5 shows the high angle XRD patterns of IBU, the mechanical mixture of IBU and HPM4, IBU stored in

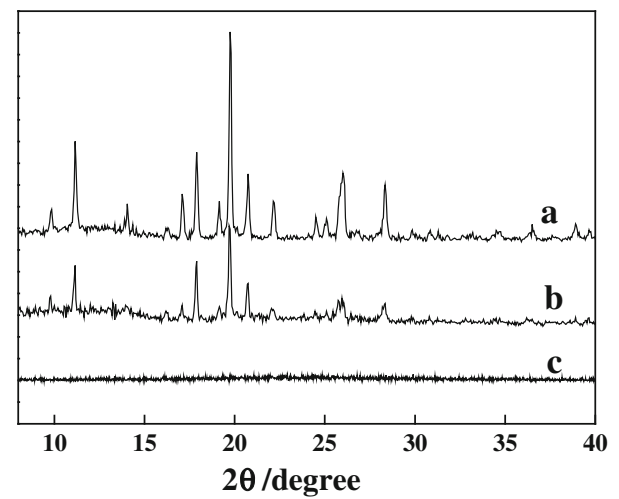

Fig. 5 XRD patterns at high diffraction angels. $a$ IBU, $b$ IBU mixed with HPM4, $c$ IBU stored in HPM4
HPM4. It can be seen that the IBU and the mechanical mixture exhibited obvious XRD spectrum peak of the drug, it indicated that the drug molecules exist still crystal form, and the assembly does not appear the diffraction peaks of the drug, it indicated that the drug molecules has loaded into the mesopores of the material [42].

Figure 6 shows the cumulative release profile of the samples in buffer solution of $\mathrm{pH}=6.8$. It can be observed that IBU showed a similar, two-step release behavior for both samples with an initially fast and a relatively slow subsequent release through the whole period. About 20 and $45 \mathrm{wt} \%$ of the IBU were released from HPM4 to HPM5 within $1 \mathrm{~h}$, respectively, but the IBU release reached similar values of 58.3 and $59.1 \mathrm{wt} \%$ when the release rate approached zero after $48 \mathrm{~h}$. Maybe this is because that the

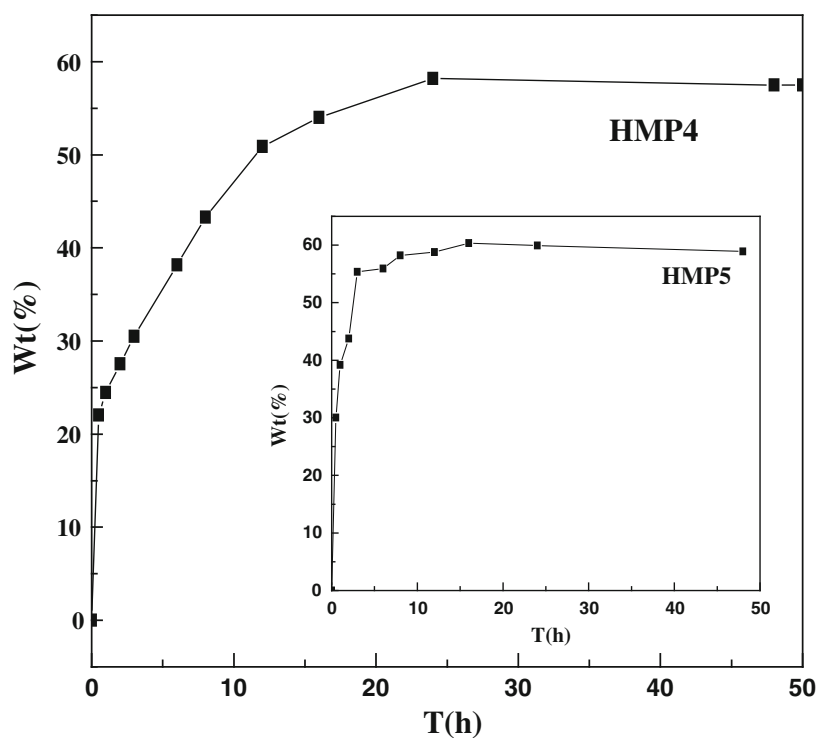

Fig. 6 Drug release kinetics of hierarchically pore silica HPM4, HPM5 
Fig. 7 SEM images of the MMBG1 before and after soaking in the SBF solution for 1, 3, 5 days. a Before soaking, b after soaking 1 day, $\mathbf{c}$ after soaking 3 days, $\mathbf{d}$ after soaking 5 days
Fig. 8 SEM images of the MMBG2 before and after soaking in the SBF solution for 1, 3, 7 days. a Before soaking, b after soaking 1 day, $\mathbf{c}$ after soaking 3 days, $\mathbf{d}$ after soaking 7 days
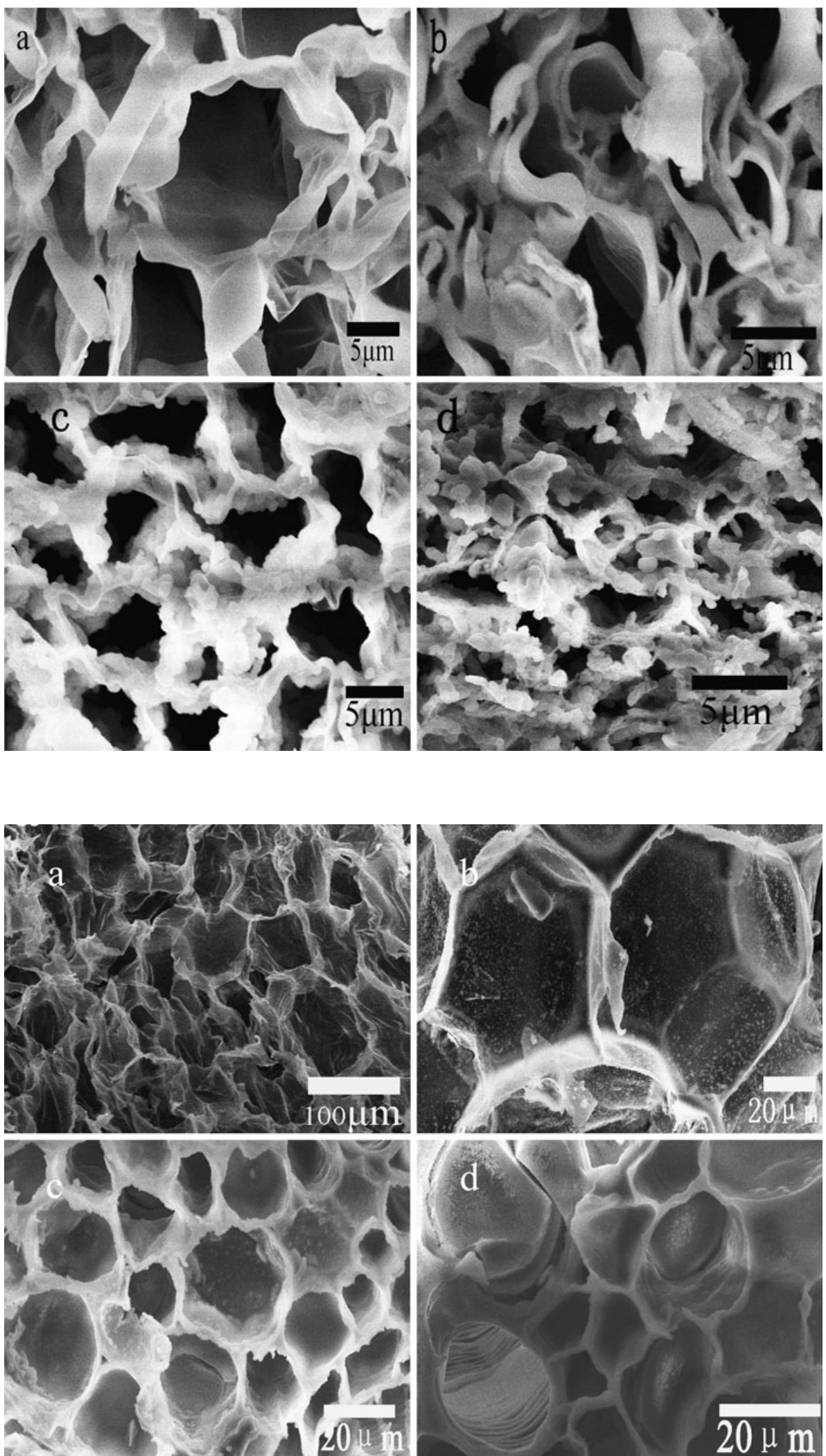

specific surface area is mainly determined by the mesoporous phase. The drug was mainly loaded in the mesoporous channels, and only a little amount was adsorbed on the macropore surface. The release of the drug from the pore materials may involve: solvent diffusion into the mesopores with dissolution of the drug, followed by its 
Fig. 9 SEM images of the MMBG3 before and after soaking in the SBF solution for $1,3,5$ days. a before soaking b after soaking 1 day $\mathbf{c}$ after soaking 3 days $\mathbf{d}$ after soaking 5 days

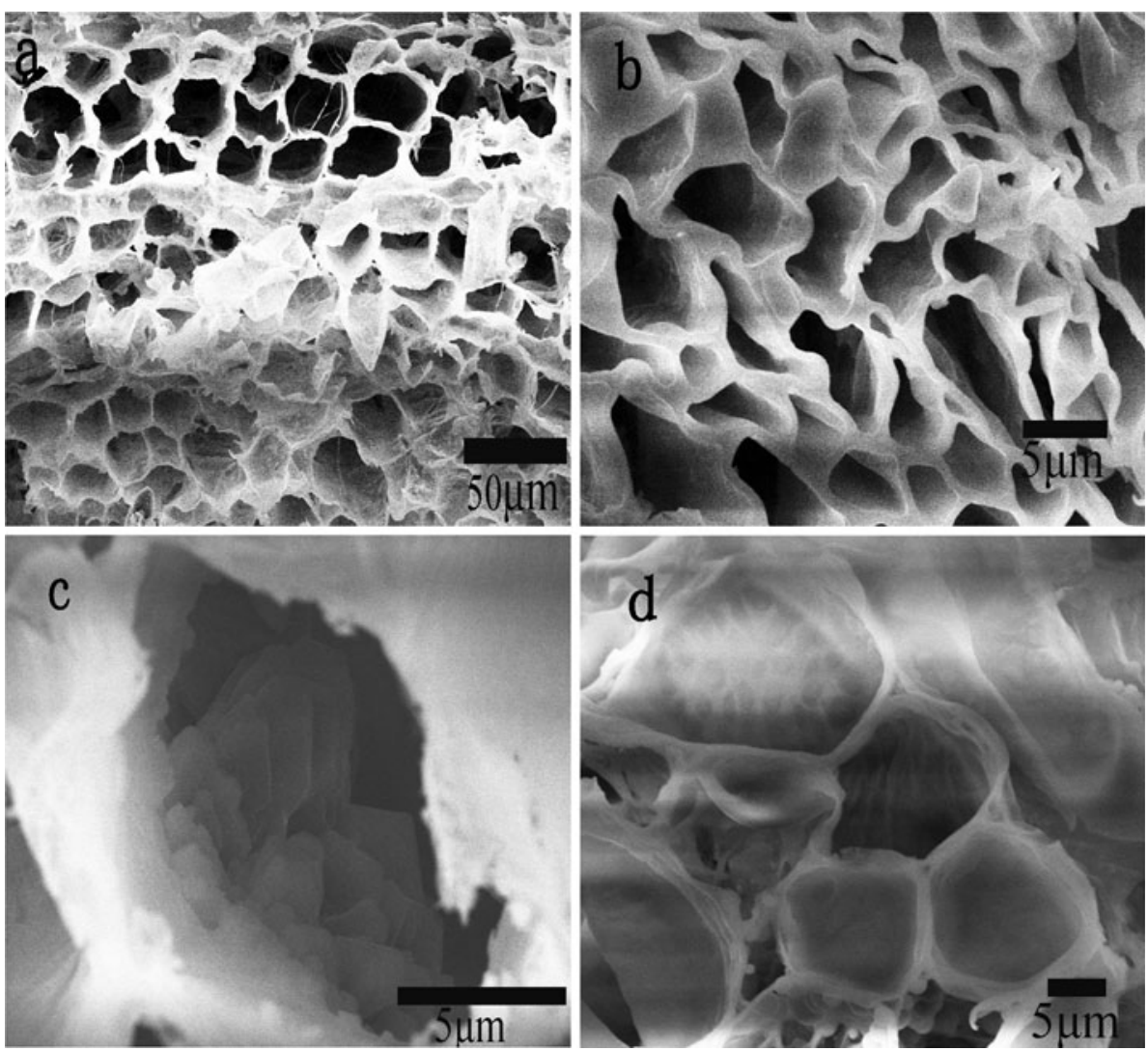

release from the mesopores into the macropores, and eventually release of the drug from the macropores to the outside solution. Thus, the macropores shall play a buffer role in the drug release. When the drug concentrations in the macropores and outside medium reached a homeostatic equilibrium, then drug molecules were no longer released from the pores. Consequently the drug could not be released completely.

\subsection{Bioactivity of the hierarchically porous bioactive glass scaffolds}

The ability to bond with living bone through a HAP interface layer on their surface is a significant characteristic of MMBGs, which has been widely studied both in vitro and in vivo [43]. The deposition/growth of HAP of the scaffolds in vitro has been investigated here by soaking them in SBF at $37{ }^{\circ} \mathrm{C}$. SEM images of the scaffolds before and after soaking for 1, 3, 5 or 7 days are shown in Figs. 7, 8 and 9. It can be seen that before soaking the three MMBGs show a smooth and homogeneous surface. After 1 day soaking, the different morphologies of HAP appeared inside the large pores and surface of the samples. Spherical HAP has grown inside the macropores of MMBG1 and MMBG2 while layered HAP formed inside the macropores of MMBG3. After 3 days the macropores and the outer surface of the bio-glasses had been almost

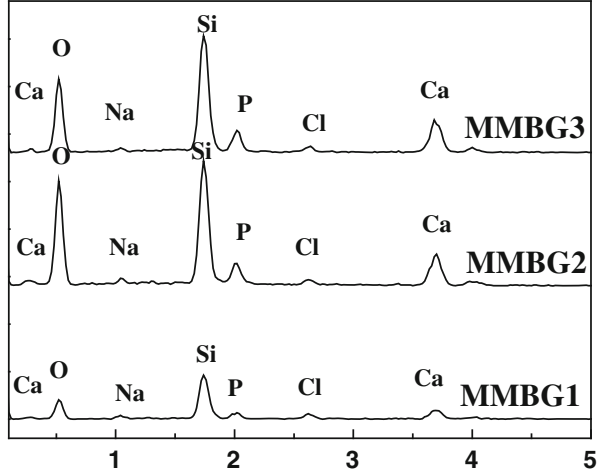

Fig. 10 EDS spectra of sample MMBG1, MMBG2 and MMBG3 immersed for 7 days

completely covered by HAP particles. At the same time, the macropore walls had become thicker gradually. After 5 days almost all macropores of MMBG1 and MMBG3 were blocked and HAP had completely covered the sample surface, whereas it needed 7 days for MMBG2 to reach that state. The reason may be that the pore size of MMBG2 is larger than those of MMBG1 and MMBG3. There are different morphologies and growth speed of HAP for the three bio-glasses, which may meet different demands of practical bone regeneration.

The EDS results of the glasses through 7 days immersion (Fig. 10) indicate that the precipitated layers are 
Fig. 11 a $\mathrm{Ca}, \mathrm{P}, \mathrm{Si}$ concentration change with soaking time in SBF after MMBG1 being soaked by ICP measurement. b Variations of $\mathrm{Ca}, \mathrm{Si}, \mathrm{P}$ of the average quality ratio on the surface of MMBG1 by EDS measurement
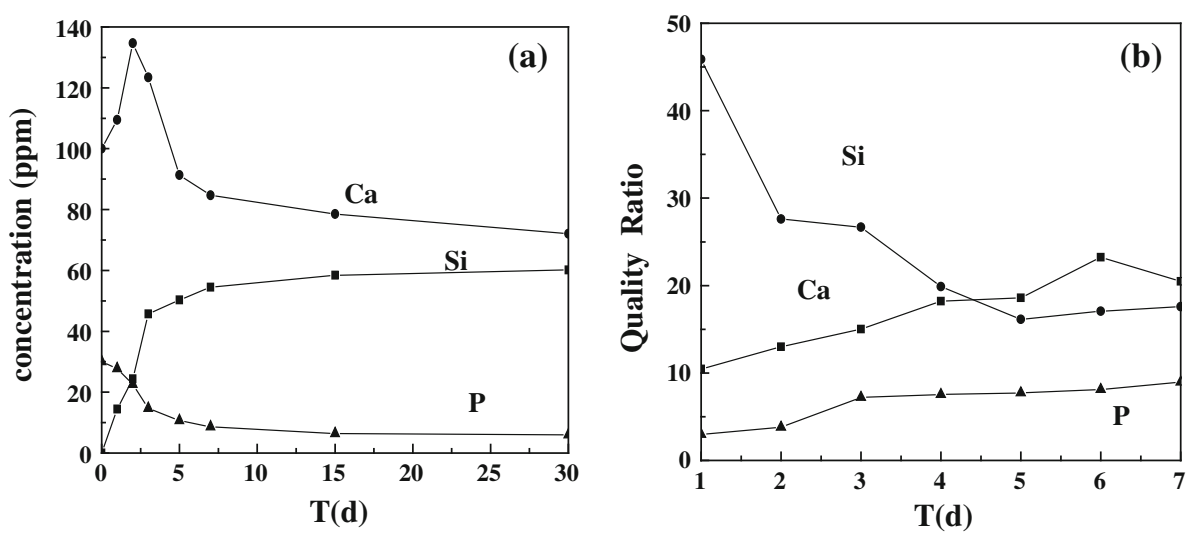

composed of $\mathrm{Ca}$ and $\mathrm{P}$ with a $\mathrm{Ca} / \mathrm{P}$ atomic ratio of 1.61 (MMBG1), 1.63 (MMBG2) and 1.72 (MMBG3), respectively. The atomic ratios are close to the theoretical value $1.67 \mathrm{Ca} / \mathrm{P}$ ratio of apatite [44]. Figure 11a shows that the concentrations of $\mathrm{Ca}, \mathrm{Si}$, and $\mathrm{P}$ in $\mathrm{SBF}$ for various immersion periods. The results indicate that silicon was released from the glasses, while calcium and phosphate were deposited on their surface, as reported by $\mathrm{Li}$ et al. [36]. The Si content increase with extension of soaking time, while the concentration of $\mathrm{P}$ decreased continually, because phosphorus diffused slowly from the samples in SBF. The $\mathrm{Ca}^{2+}$ concentration is controlled by both the release of $\mathrm{Ca}^{2+}$ from the sample and the formation of HAP. The $\mathrm{Ca}^{2+}$ concentration increased during the first 3 days for the rapid calcium dissolution; and then decreased slowly, the reason can be attributed to the rapid growth of the apatite nuclei formed on surface of the sample, which overcame the release rate of $\mathrm{Ca}^{2+}$ to the solution. It can be concluded that a HAP layer has formed from SBF to the samples, and the materials can induce the growth of HAP on their surface. On the other hand, EDS analysis of $\mathrm{Ca}, \mathrm{Si}$, and $\mathrm{P}$ on the sample surfaces during different times (Fig. 11b) roughly indicated that $\mathrm{Ca}$ and $\mathrm{P}$ increased continually while $\mathrm{Si}$ decreased. This also confirmed the growth of HAP on the surface of the samples. Results indicated that these novel bioactive glass scaffolds with good bioactivity can induce the formation of HAP layers in SBF, and thus may have potential application in tissue regeneration engineering.

\section{Conclusions}

In summary, for the first time we reported the synthesis of a series of highly ordered, porous silica and bio-glasses with large pore sizes of $8-1000 \mu \mathrm{m}$ and mesopore sizes of $3-5 \mathrm{~nm}$ using six plants as templates. The novel porous silica materials exhibit sustained drug delivery profiles, and the porous bioactive glass scaffolds can induce the precipitation of HAP layers on their surface in SBF within
1 day, which are converted into crystalline HAP within 7 days. The morphologies and the growth speed of HAP differ for the three MMBGs, so it is difficult to come to a clear conclusion about the optimum macropore size for bone regeneration. The unique interconnected multimodal porosity distribution and excellent in vitro bioactivity of MMBGs make them a good candidate for bone regeneration and drug delivery.

Acknowledgments Financial support for this study was provided by the National Native Science Foundation of China (20871037, 21171045, 21101046), Innovation special fund of Harbin Science and Technology Bureau of China (2010RFXXS055), Program for Scientific and Technological Innovation team Construction in Universities of Heilongjiang province (2011TD010), and Doctoral Initiation Fund of Harbin Normal University (KGB201006).

Open Access This article is distributed under the terms of the Creative Commons Attribution License which permits any use, distribution, and reproduction in any medium, provided the original author(s) and the source are credited.

\section{References}

1. Yuan ZY, Su BL (2006) J Mater Chem 16:663-667

2. Zhao DY, Yang P, Chmelka BF, Stucky GD (1999) Chem Mater 11:1174-1178

3. Sun J, Li YS, Li L (2008) J Non-Cryst Solids 354:3799-3805

4. Cai XH, Zhu GS, Zhang WW, Zhao HY, Wang C, Qiu SL, Wei Y (2006) Eur J Inorg Chem 18:3641-3645

5. Lee YJ, Lee JS, Park YS, Yoon KB (2001) Adv Mater 13:1259_ 1263

6. Andeson MW, Holmes SM, Hanif N, Cundy CS (2000) Angew Chem Int Ed 39:2707-2710

7. Sen T, Gordon GT, John TT, Casci JL, Anderson MW (2003) Angew Chem Int Ed 42:4649-4653

8. Holland BT, Abrams L, Stein A (1999) J Am Chem Soc 121:4308-4309

9. Sen T, Anderson MW (2004) Chem Mater 16:2044-2054

10. Zhu G, Qiu S, Tearsaki O (2001) J Mater Chem 11:1687-1693

11. Antonietti M, Berton B, Goltner C, Hentze HP (1998) Adv Mater 10:154-159

12. Lee YJ, Yoon KB (2005) Micro Meso Mater 88:176-186

13. Zhang H, Hardy GC, Rosseinsky MJ, Cooper AI (2003) Adv Mater 15:78-81 
14. Yue WB, Park RJ, Kulak AN, Meldrum FC (2006) J Cryst Growth 294:69-77

15. Zhang BJ, Davis SA, Mann S (2000) Chem Comm 35:781-782

16. Valtchev V, Smaihi M, Vidal L (2003) Angew Chem Int Ed 42:2782-2785

17. Huang LM, Wang HT, Hayashi CY, Tian B, Zhao DY, Yan YH (2003) J Mater Chem 13:666-668

18. Shin YS, Liu J, Chang JH, Nie ZM, Exarhos GJ (2001) Adv Mater 13:728-732

19. Dong AG, Wang YJ, Tang Y, Ren N, Zhang YH, Yue YH, Gao Z (2002) Adv Mater 14:926-929

20. Chaisena A, Rangsriwatananon K (2005) Mater Lett 5:14741479

21. Wataru O, Wayne S, Sean AD, Stephen M (2000) Chem Mater 12:2835-2837

22. Meldrum FC, Seshadri R (2000) Chem Commun 35:29-30

23. Valtchev V, Smaihi M, Faust AC, Vidal L (2004) Chem Mater 16:1350-1355

24. Wang YJ, Tang Y, Dong AG, Wang XD, Ren N, Gao Z (2002) J Mater Chem 12:1812-1818

25. Hall SR, Bolger H, Mann S (2003) Chem Commun 22:27842785

26. Yang D, Qi LM, Ma JM (2002) Adv Mater 14:1543-1546

27. Cook G, Timms PL, Spickermann CG (2003) Angew Chem Int Ed 42:557-559

28. Davis SA, Burkett SL, Mendelson NH, Mann S (1997) Nature 385:420-423

29. Shinye C, Jun U, Fuyuhiko T, Bruce D, Jeffrey IZ (2000) J Am Chem Soc 122:6488-6489
30. Lei B, Chen X, Wang Y, Zhao N, Chang D, Fang L (2009) J NonCryst Solids 355:2678-2681

31. Kokubo T, Matsushita T, Takadama H, Kizuki T (2009) J Eur Ceram Soc 29:1267-1274

32. Vallet-Regi' M, Ruiz-Gonza'lez L, Isabel-Barba I, Gonza'lezCalbet JM (2006) J Mater Chem 16:26-31

33. Jing Y, Wei G, Huang X, Zhao L, Zhang Q, Yu C (2008) J SolGel Sci Technol 145:115-119

34. Hench LL, Splinter RJ, Allen WC, Greenlee TK (1971) J Biomed Mater Res 2:117-141

35. Mohamad Yunos D, Bretcanu O, Boccaccini AR, Aldo R (2008) J Mater Sci 43:4433-4442

36. Xia L, Wang X, Chen H, Jiang P, Dong X, Shi J (2007) Chem Mater 19:4322-4326

37. Li N, Jie Q, Zhu S, Wang R (2005) Ceram Int 31:641-646

38. Vallet-Regi M (2006) Dalton Trans 44:5211-5220

39. Kokubo T, Kushitani H, Sakk S, Kitsugi T, Yamamuro T (1990) J Biomed Mater Res 24:721-734

40. Saravanapavan P, Jones JR, Oryce RS, Hench LL (2003) J Biomed Mater Res 66A:110-119

41. Li X, Jiang J, Yu W, Nie X, Qu F (2010) J Sol-Gel Sci Technol 56:75-81

42. Liu CJ, Li SG, Pang WQ (1997) Chem Commun 1:65-66

43. Izquierdo-Barbaa I, Ruiz-Gonzálezb L, Doadrioa JC, GonzálezCalbetb JM, Vallet-Regí M (2005) Solid State Sci 7:983-989

44. Olmo N, Martin AI, Salinas AJ (2003) Biomaterials 24:33833393 